\title{
ANAESTHETIC REGIME FOR PROLONGED OPERATIONS IN SWINE
}

\author{
J.N. Gummoncs, PH.D.," W.H. HarRIS, D.v.M., M.SC., $\nmid$ \\ AND J.L. Agar, D.v.M., M.sc.f
}

IN RECENT YEARS there has been an increased use of swine for experimental surgery, physiology and microbiology. Also, the incidence of caesarian sections in swine has increased primarily for the establishment of commercial S.P.F. (specific pathogen free) herds and for the production of gnotobiotic newborn piglets. In general, swine respond favourably to most anaesthetics and anaesthetic regimes which render the species suitable to a large variety of experimental procedures requiring modifications in anaesthesia. Barbiturate-muscle relaxant-nitrous oxide anaesthesia has been used successfully in humans for prolonged thoracic and abdominal operations and in caesarian sections. ${ }^{1-5}$ The action and efficacy of the anaesthetics used in this general procedure have been discussed proficiently by Dam and Guldman ${ }^{\star}$ with particular emphasis on postanaesthetic ventilation.

Our research program on foetal physiology in swine required prolonged surgical procedures on pregnant sows in order to complete studies of all the foetuses within each litter. General anaesthesia using methoxyflurane or halothane with or without nitrous oxide was found inadequate due to variability in haemodynamics, inconsistency in level of anaesthesia, depression of the foetuses, and a high incidence of anaesthetic deaths during prolonged procedures. It was decided therefore to adapt to swine the principles from the procedures developed by Cohen et al., and Hartridge and Wilson, ${ }^{3}$ procedures which were used successfully for caesarian sections in humans.

\section{Materlals and Methods}

A modification of thiopentone-curare-nitrous oxide anaesthesia was developed and used on 67 pregnant sows of Yorkshire-Landrace-Hampshire-Duroc breeding that ranged in weight from 165 to $323 \mathrm{Kg}$. The operations performed involved laparotomies and hysterotomies for studies on experimental foetal physiology and the development of techniques for operations on the foetus as outlined in Table I. The operations were performed on 49 sows between 110 and 113 days gestation and on 18 sows between 70 and 83 days gestation (total gestation in swine averages 114 days). The duration of anaesthesia required ranged from five to thirteen hours.

Food was withheld for 24 hours and water for 12 hours preceding the induction of anaesthesia. No premedication was used. Induction was accomplished by intravenous injection of thiopentone ( 2.5 per cent aqueous solution) via an ear

- Department of Clinical Studies, Ontario Veterinary College, University of Guelph.

†Department of Biomedical Sciences, Ontario Veterinary College, University of Guelph.

tDepartment of Clinical Studies, Western College of Veterinary Medicine, University of Saskatchewan. 
TABLE I

Various Experiments Requiring Prolonged Sergical Anaesthesia

\begin{tabular}{|c|c|c|c|}
\hline Surgical procedure & $\begin{array}{l}\text { No. of sows } \\
\text { used }\end{array}$ & $\begin{array}{l}\text { Size of } \\
\text { litter } \\
\text { ave. } \\
\text { (tange) }\end{array}$ & $\begin{array}{l}\text { No. deaths of } \\
\text { sows during or } \\
\text { following surgery }\end{array}$ \\
\hline $\begin{array}{l}\text { Studies of foetal haematology and } \\
\text { endocrinology }\end{array}$ & 18 & $\begin{array}{l}10.8 \\
(3-15)\end{array}$ & 0 \\
\hline $\begin{array}{c}\text { Effects of varying levels of oxygen intake } \\
\text { by the sow on foeti in utero at term }\end{array}$ & 25 & $\begin{array}{l}11.7 \\
(7-16)\end{array}$ & $5^{*}$ \\
\hline Experimental foetal piglet surgery & 13 & $\begin{array}{l}10.6 \\
(7-13)\end{array}$ & 11 \\
\hline Caesarian sections & 4 & $\begin{array}{l}10.0 \\
\{4-16\}\end{array}$ & 0 \\
\hline $\begin{array}{l}\text { Studies on umbitical cord reactivity } \\
\text { Studies on foetal immunology }\end{array}$ & $\begin{array}{l}2 \\
5\end{array}$ & $\begin{array}{l}11.0 \\
8.0 \\
(4-10)\end{array}$ & 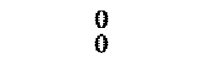 \\
\hline Total & 67 & & 6 \\
\hline
\end{tabular}

*Three sows died following operations of 12 hours each due to prolonged exposure to induced hypoxia, resulting in failure to establish spontaneous respiration.

One large sow (280 $\mathrm{Kg}$ ) died from cardiac failure after six hours of operation and exposure to induced hypoxia.

One sow died from laryngospasm following an operation af ter the endotracheal tube was removed. tThis sow died 2 hours following surgery, inadequate post-operative ventilation.

vein using doses "to effect" which varied from 2.50 to $6.25 \mathrm{gm}$. Thiopental was injected rapidly to start with until the animal began to drop, then slowly until induction was complete. Variation in the amount of thiopentone depended upon the individual, the lapse of time before completion of intubation and the weight of the sow. No reliable dosage-weight relationship was found. Just prior to induction, the sow was tied securely with a rope around the upper jaw and both ears were clipped and disinfected. The intravenous route, used to inject the thiopentone and later to administer intravenous fluids and drugs, was established by inserting a winged infusion cannula ( 18 or 19 gauge) into one of the more prominent ear veins, preferably the marginal vein. Normal saline was then flushed through the cannula to ensure that the needle was in the vein. The cannula was then taped securely to the ear and again flushed with normal saline before administering the thiopentone. Frequently, the winged infusion cannula was replaced with a pliable plastic cannula from an angiocatheter ( 16 gange) after the induction had been completed and the ear veins had dilated.

In many cases a prolonged period lapsed between the initial induction, tracheal intubation and the establishment of maintenance anaesthesia and mechanical respiration, due to the fact that anaesthesia had to be introduced in the barn and the animals then transferred some distance to the operating room. This required maintenance with intermittent injections of additional thiopentone, and in a few cases respiration was depressed. Artificial respiration was applied with a "mouth-tomouth" technique by closing the mouth with one hand, placing a thumb over one of the nostrils and breathing into the other nostril. This proved to be a most effective 


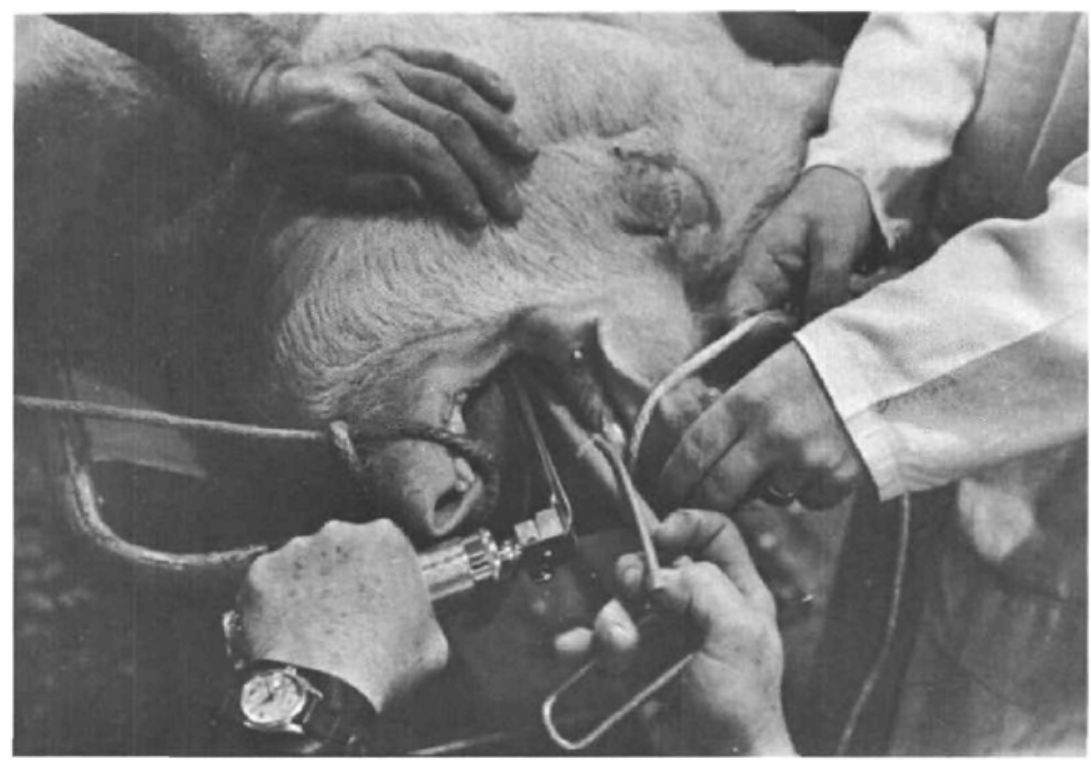

Ficure 1. Endotracheal intubation of the sow after induction. Note the metal stylet inserted into the endotracheal tube.

procedure requiring not more than 10 minutes of assisted respiration before spontaneous respiration was re-established. In no case was the application of pressure on the chest wall found effective because the rib cage of adult swine is too rigid.

In the early stages of these experiments succinylcholine was given intravenously or intramuscularly to 15 sows after intubation to test this drug as a muscle relaxant in swine. The dose per animal, regardless of weight, which produced muscle paralysis including a depression of respiration was $160 \mathrm{mg}$. Mechanical respiration was applied and the paralyzing effects of the drug were noted to last ten minutes in each case. As a result, succinylcholine was always kept on hand during the barbiturate induction in case the cannulation failed with a partial induction resulting, including an excitatory stage. Then, if necessary, succinylcholine (160 mg) could be given intramuscularly and artificial respiration could be applied until another cannulation was made to complete the barbiturate induction. We emphasize this precaution, because superficial veins are difficult to locate in swine and we have on other occasions witnessed animals during the excitatory stage with incomplete thiopentone or pentabarbitone inductions.

Endotracheal intubation using a cuffed tube (Rusch, $15 \mathrm{~mm} \times 50 \mathrm{~cm}$ ) with a straight metal stylet inserted was accomplished while the sow was under thiopentone anaesthesia (Figure 1). The use of succinylcholine at this point was tried two or three times but discontinued, because the drug did not increase jaw relaxation and only enhanced the risks involved with depressed respiration. A 
laryngoscope with a slightly curved blade $40 \mathrm{~cm}$ long was used. Extreme care was used in passing the end of the tube through the larynx and into the trachea because even slight trauma will cause excessive haemorrhage from rupture of an artery in a depression on the floor of the larynx anterior to the cricoid cartilage.

With intubation completed, a gaseous mixture of oxygen and nitrous oxide, in ratios of $1: 1$ or $1: 2$, was delivered to the sow by means of a Bird Mark 8 respirator and a Bird Mark 4 assistor/controller. The flow rate was six to eight liters per minute, the tidal volumes varied from 900 to $1800 \mathrm{ml}_{\text {, }}$ and the inspiratory pressure was maintained between 15 and $20 \mathrm{~cm}$ of water. The initial dose of $30 \mathrm{mg}$ of d-tubocurarine was given intravenously immediately after starting the administration of the oxygen-nitrous oxide. Muscular paralysis, including depression of respiration, ensued and positive pressure mechanical respiration was used throughout the entire surgical procedure. Duration of the paralytic effects of each dose of d-tubocurarine varied from 20 to 60 minutes, usually 45 minutes. Subsequent doses of 12 to $15 \mathrm{mg}$ of d-tubocurarine were given as required, indicated by movement of the tongue and initiation of spontaneous respiration.

A continuous intravenous drip of dextrose ( 5 per cent) in lactated Ringer's solution was maintained throughout, via the ear vein cannula. The EKG was monitored continuously using lead II or lead III. In those sows used in the studies on varying levels of oxygen intake, the saphenous artery in the right hind leg was exposed and cannulated with a 15-gauge surgical venocatheter from which blood pressure was recorded via a Statham pressure transducer. In this same group arterial blood samples for determinations of oxygen saturation, haemoglobin concentration, $\mathrm{pH}$ and partial pressure of carbon dioxide were withdrawn from the same cannula.

All sows had been placed on the operating table in a right lateral recumbency as all operations involved left flank laparotomies. A vertical incision, 30 to 35 $\mathrm{cm}$ long, was made beginning eight to ten $\mathrm{cm}$ below the spinal transverse processes in the mid-lumbar region and extending in a straight line through the flank to three to five om above the mammary line (Figure 5). The muscle layers were transected and the peritoneum was opened in the same plane as the skin incision. The site of incision was infiltrated with lidocaine (2 per cent) with epinephrine $(1: 100,000)$ and the peritoneal surfaces of the uterus were sprayed with lidocaine ( 2 per cent) without epinephrine in order to increase analgesia.

After the foetal studies were completed and the foetuses delivered, the curare was reversed by first giving one $\mathrm{mg}$ of atropine sulfate followed by three $\mathrm{mg}$ of neostigmine intravenously and both were repeated five minutes later. The oxygen-nitrous oxide mixture in a ratio of $1: 1$ was maintained and approximately 0.5 to 1.0 per cent methoxyelurane was added. The latter was administered for 30 to $\mathbf{4 5}$ minutes during the closure of the abdominal wall primarily for its post-operative analgesic effects. Thus completed, only oxygen was given until spontaneous respiration was well established.

Figure 2 shows the general set-up for anaesthesia and operation during one of the experiments in which all foetuses were sampled for haematological data in utero requiring an operation lasting 12 hours. 


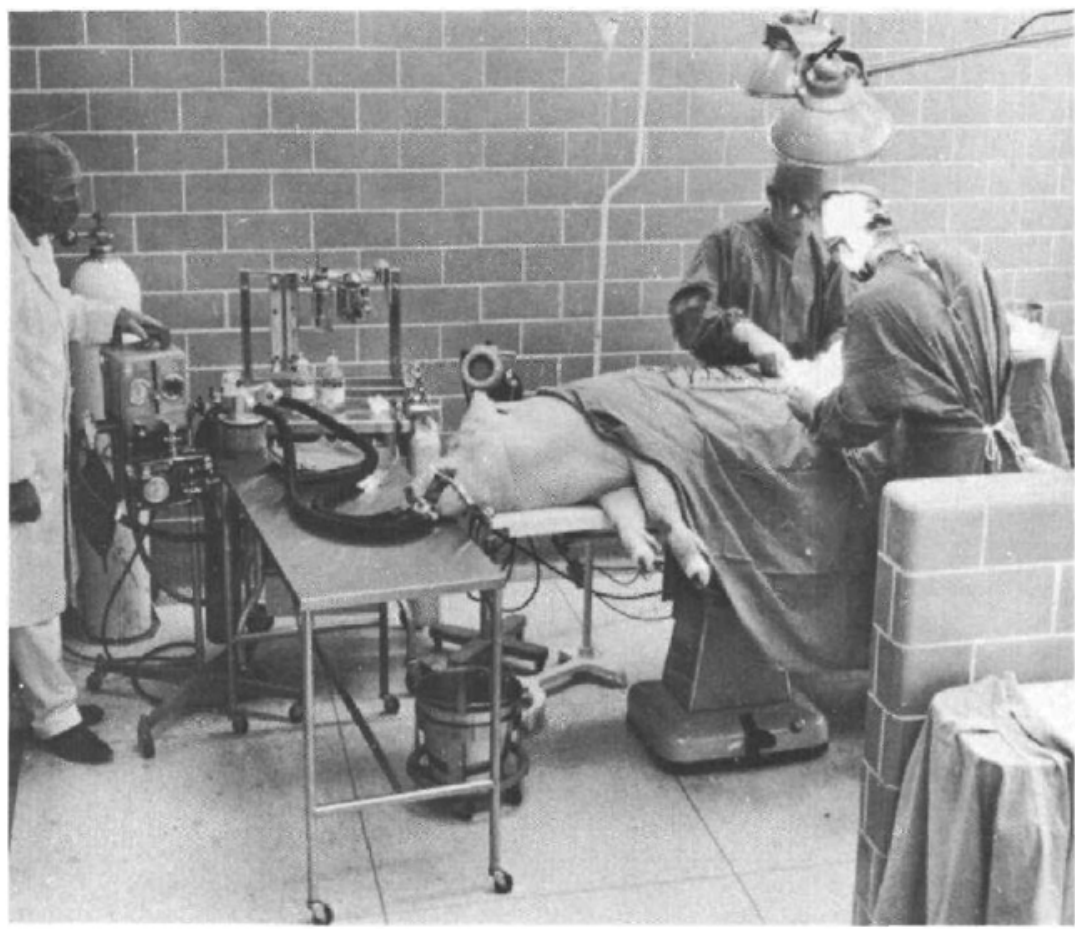

Frcure 2. General set-up for anaesthesia and surgery during an experiment on foetal haematology.

\section{Results}

The various operations in which this anaesthesia regime was used are listed in Table I, along with the number of sows used, litter size and fatalities. Only six sows out of 67 died during or following the prolonged operations and four of these deaths could be attributed primarily to exposure to induced severe hypoxaemia for two to three hours during the experiments. Three of these were alive at the end of the operation but failed to regain spontaneous respiration because of severe respiratory and metabolic acidosis.

Physiological data from one sow which was anaesthetized for nine hours using this procedure, but not exposed to induced hypoxia, are presented in Figures 3 and 4 . Ten viable foetuses at 112 days gestational age were sampled in utero and removed. In 20 sows in which the same parameters were recorded for four hours of anaesthesia before hypoxia was induced experimentally, the mean heart rate was $127 \pm 14$ (S.D.) beats per minute; the mean systolic blood pressure was $158 \pm 28 \mathrm{~mm} \mathrm{Hg}$; the mean pulse pressure was $48 \pm 11 \mathrm{~mm} \mathrm{Hg}$; and the oxygen content was $15 \pm 2$ volumes per cent. The mean arterial $\mathrm{pH}$ was $7.43 \pm 0.07$ with a gradual increase during this period of time. The mean partial pressure of carbon dioxide was $35 \pm 8 \mathrm{~mm} \mathrm{Hg}$ and gradually decreased. This decrease was un- 


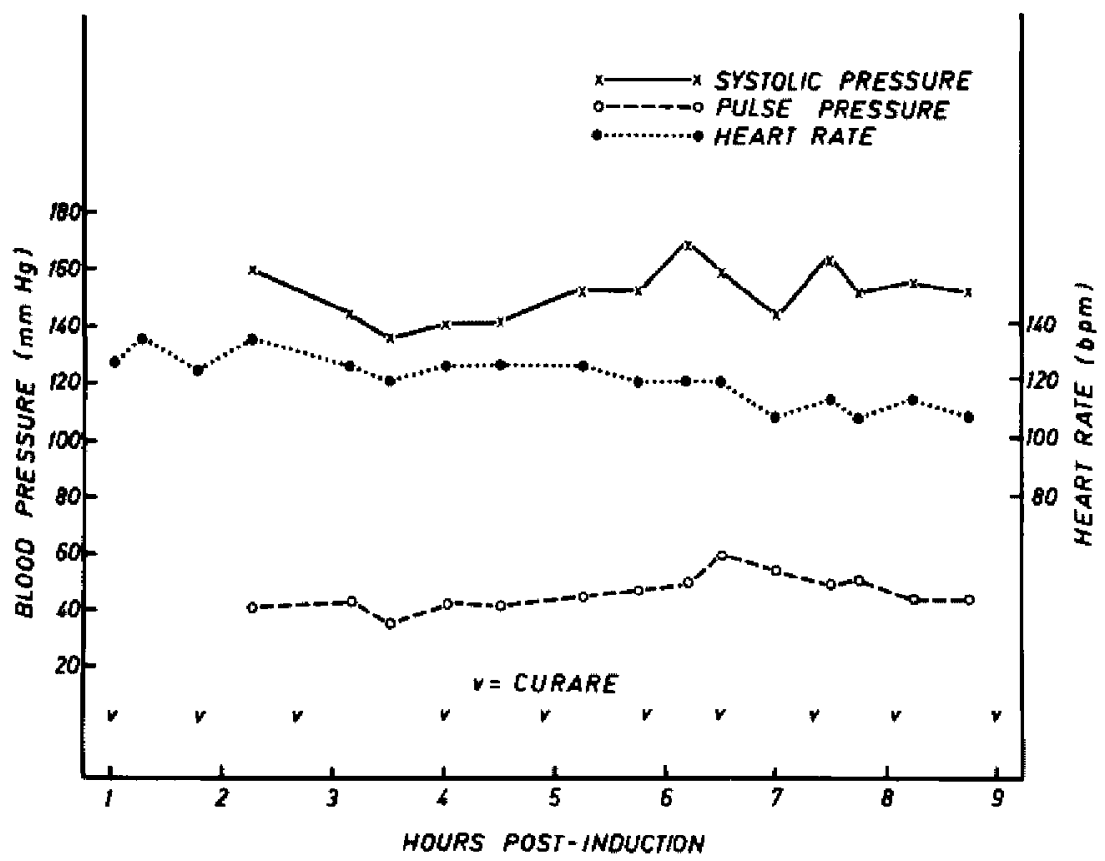

Frgune 3. Record of systolic blood pressure, pulse pressure and heart rate from one of the sows which was anaesthetized as described in the text for nine hours. A nitrous oxide-oxygen ratio of $2: 1$ was maintained throughout the regime. The operation involved foetal physiology studies in wtero.

doubtedly due to mechanical hyperventilation. In the remaining sows only the EKG was monitored.

On one occasion, with the largest sow used in this series $(323 \mathrm{Kg})$ and anaesthetized for 12 hours, heart rate had remained normal and constant during the curare-nitrous oxide phase of the regime. However, when the curare was reversed and methoxyflurane added to the gaseous mixture for the closure of the abdominal wall, tachycardia occurred followed by fbrillation. All anaesthetics were discontinued and the lungs were hyperventilated with pure oxygen. Fibrillation ceased after three minutes and a nomal EKG retumed. No further anaesthetics were given for the completion of abdominal closure. Post-operative recovery was uneventful.

Recovery from anacsthesia was smooth and no periods of excitement were observed. Most of the sows were up and moving about within four to five hours and eating within 12 hours. Recovery was unrelated to duration of anaesthesia. Some sows were rebred and used for second and third times. Figure 5 shows one of the sows two weeks after one of the operations which had lasted 12 hours.

While term foetuses were not retained for neonatal studies beyond five hours, all, except those delivered from sows during induced hypoxia, showed little 

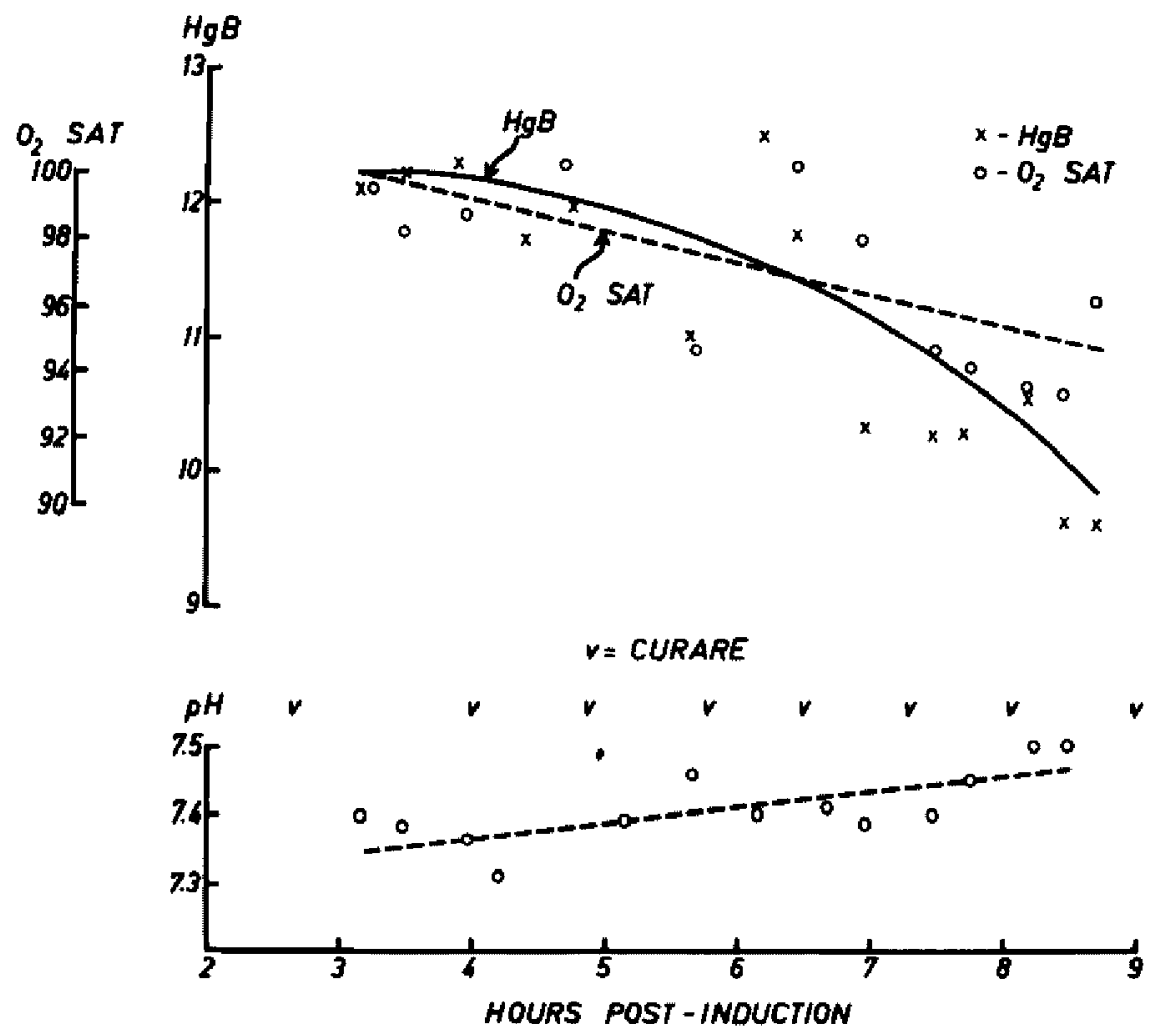

Ficure 4. Record of the changes in haemoglobin concentration, oxygen saturation and $\mathrm{pH}$ of arterial blood from the same sow referred to in Figure 3 . Blood sampling in this case did not start until three hours post-induction. Curare had been administered twice prior to the first dose indicated on this graph.

clinical evidence of depression. Their one-minute Apgar scores ranged from 7 to 10 with an average of 8.5 with no relationship to duration of anaesthesia and operation at the time of delivery. Foetal deaths and depression occurred only when the mother had been subjected to repeated exposures of severe hypoxia.

\section{Comments}

This paper is primarily a presentation of the details of a method of anaesthesia used successfully in swine where prolonged experimental operations are required and for caesarian sections. However, it is the opinion of the authors that this procedure can be used in most surgical manipulations in swine requiring general anaesthesia. This opinion is evidenced by the following: (a) a very low incidence of anaesthetic deaths, (b) uncomplicated and rapid recovery, (c) maintertance of optimal haemodynamics, (d) maintenance of a steady level of anaesthesia, and (e) the recovery of vigorous foetuses after long exposures to anaesthesia. 


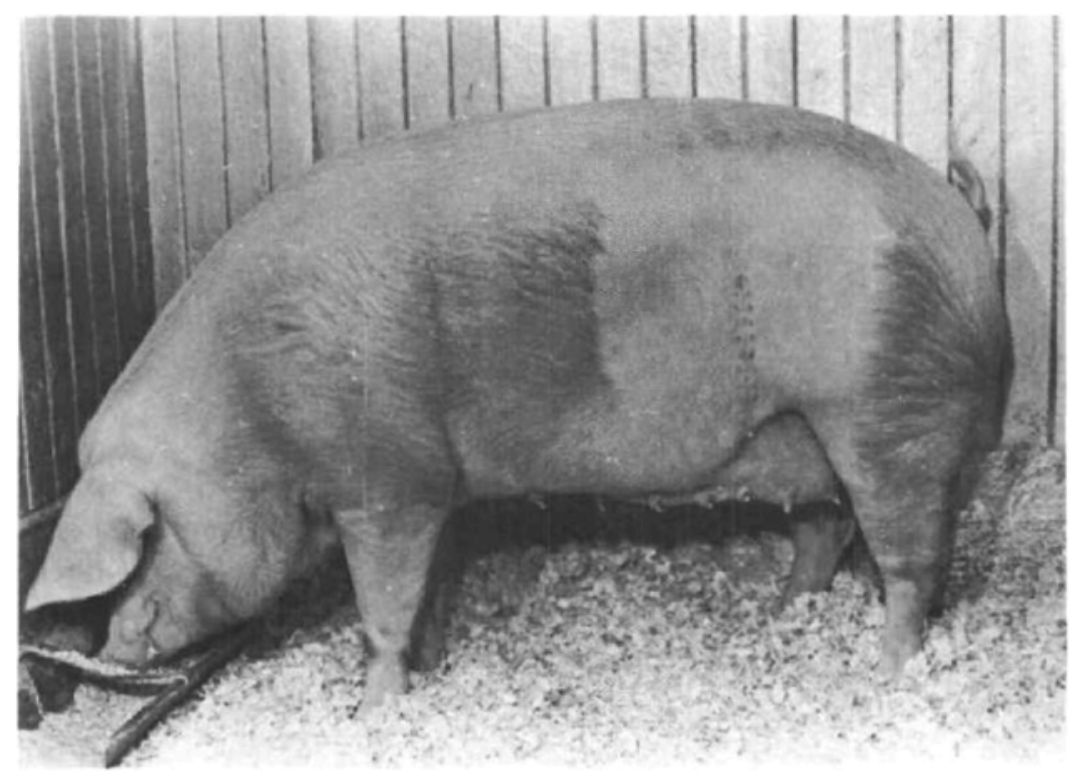

FrGune 5. One of the sows two weeks after an operation lasting 12 hours.

Of the six deaths, four were attributed to prolonged and deliberate exposure to low levels of oxygen during the experiments. Therefore only two deaths from the 67 operations reported could be related to the anaesthetic procedure - one from laryngospasm following the removal of the endotracheal tube and the other from inadequate postoperative ventilation. ${ }^{6}$

The lungs of two of the animals were examined at the time of slaughter and no gross evidence of atelectasis was found. The normal appearance of the lungs and the fact that none of the animals showed evidence of respiratory impairment during or following recovery was probably due to the fact that the tidal volumes with mechanical ventilation were higher than those with spontaneous respiration under anaesthesia. ${ }^{7}$ This also could account for the decrease in arterial partial $\mathrm{CO}_{2}$ pressure and the gradual increase in $\mathrm{pH}^{\mathrm{s}}$

The physiological data from the one sow presented in Figures 3 and 4 are quite typical of all animals where one-third oxygen was used in the gaseous mixture, with the exception of the general decline in haemoglobin concentration. In the other sows haemoglobin values remained constant at this level of oxygen intake. They were elevated during induced hypoxia and returned to base levels when oxygen intake was increased. ${ }^{8}$ Arterial oxygen saturations remained in the high ranges even though there was a slight decline near the end of anaesthesia. Blood pressure and heart rate remained constant and at optimal levels over prolonged periods up to 13 hours.

It is important to emphasize the use of liberal amounts of local anaesthetic (lidocaine) at the incision site and as a spray on the peritoneal surfaces after the abdominal cavity was opened. This was essential to increase the analgesia 
beyond that provided by the nitrous oxide administered. Laxity in this respect on the part of the surgeons was invariably reflected by tachycardia in the patient.

A significant point of this report is that all procedures, involving both anaesthesia and operation, were performed with the sows in a lateral recumbency. Previous experience with this method of anaesthesia or with methoxyfuranenitrous oxide anaesthesia had demonstrated that venous return was seriously impaired after one or two hours, resulting in heart failure and death, if the animal was placed in a dorsal recumbency. Of course, pregnancy aggravated the situation; perhaps with non-pregnant swine of smaller size this may not be as serious. However, one must be cognizant of the fact that respiration in swine, whether spontaneous, assisted or mechanically controlled, is almost completely by diaphragmatic movement and the rib cage remains quite rigid. Muscle relaxing anaesthetics, particularly, allow a shift of the organs in the thoracic and abdominal cavities resulting in increased pressure on the vena cava.

Malignant hyperthermia occurs in swine due to a genetic defect. ${ }^{8}$ Two spontaneous cases, not included in this series, occurred in our experience. In one case succinylcholine and halothane were used for induction and in the second, extreme excitement triggered an episade without the use of any drugs. ${ }^{\circ}$ Precaution in handling the animals prior to, or during induction is therefore essential, especially if succinylcholine is used where a barbiturate induction has failed as suggested in the procedure.

In addition to experimental surgery, this anaesthetic procedure could be extremely useful during caesarian sections in swine where S.P.F. newborn piglets are required or for the delivery of gnotobiotic piglets, now required in increasing numbers for research on specific pathogenic bacteria and viruses. The viability of the foetuses delivered with the above anaesthesia was excellent. There was little or no clinical evidence of depression due to anaesthesia providing the nitrous oxide concentration did no exceed 67 per cent and providing 45 to 60 minutes were allowed to elapse from the time of induction until delivery. The latter, of course, was needed because of the large amounts of thiopentone used in our series. The amount of barbiturate used for induction could be drastically reduced by bringing the sows closer to the operating rooms and thus decreasing the time required between induction and curarization. The duration of thiopentone depression of the foetus would thereby be markedly reduced..$^{3.11,12}$ No evidence of transplacental passage of curare was experienced.

\section{SUMMARY}

A modification of thiopental-curare-nitrous oxide anaesthesia for use in operations lasting up to 13 hours was developed and used on 67 pregnant sows. Of the six fatalities only two could be directly attributed to anaesthesia responses. Optimal haemodynamics and a constant steady level of anaesthesia were maintained throughout the entire procedure. There was little or no anaesthetic depression of the foetuses delivered by caesarian section. Recovery from anaesthesia was smooth and uncomplicated. Details of the procedure have been presented in the text. 


\section{Résumé}

Une modification de l'anesthésie au pentothal-curare-protoxide d'azote pour des interventions d'une durée allant jusqu'à 13 heures a été utilisée chez 67 truies en période de gestation. Deux seulement des six morts pouvaient être attribuées à l'anesthésie. On a obtenu des données hémodynamiques idéales et un niveau constant d'anesthésie durant tout le cours des interventions. Il y eut peu ou pas de dépression anesthésique chez les foetus mis au monde par césarienne. Le réveil s'est effectué doucement et sans complications. On a présenté dans le texte les détails de cette technique.

\section{ACKNOWLEDGMENTS}

This research was supported by grants in aid from the National Research Council of Canada (Grant No. A-3639). Financial assistance from the Ontario Department of Agriculture and Food for this project is gratefully acknowledged. Sincere appreciation is credited to Mrs. R. Dingwall for her technical assistance and to the many clinical students at the Ontario Veterinary College for their interest and long hours expended in surgery and laboratory assistance during the course of these investigations.

\section{REFERENCES}

1. Coupre, J.L. The use of curare in prolonged abdominal operations. Anesth. \& Anal. 26: $231(1947)$.

2. DYKEs, M.H. Evaluation of nitrous oxide and a nondepolarizing muscle relaxant for prolonged surgery. Anesth. \& Analg, 48; 257 (1969).

3. Hantaider, V.D. \& WiLsoN, R.B. Balanced anesthesia for cesarian section. Amer. J. Obstet. \& Gynec. 85:619 (1963).

4. Cohen, E.N., Paulson, W.J., Wall, J., \& Elbert, B. Thiopental, curare, and nitrous oxide anesthesia for cesarian section with studies on placental transmission. Surg. Cynec. \& Obstet. 97: 456 (1953).

5. CohEn, E.N. Thiopental-curate-nitrous oxide anesthesia for cesarian scetion. Ancsth. \& Analg. 4I: 122 ( 1962 ).

6. DAM, W.H. \& GuLdmanN, N. Inadequate postanesthetic ventilation. Curare, anesthetic, narcotic, diffusion hypoxia. Anesthesiology 22: 699 (1961).

7. MCDONELL, W.N. Ventilation and acid-base equilibrium with methoxyflurane anesthesia in dogs. M.Sc. Thesis, Univ. of Guelph, (1969).

8. Hafars, W.H. Response of the pregnant sow at term and her fetuses to varying levels of oxygen intake. M.Sc. Thesis, Univ. of Guelph (1971)

9. Befman, M.D., Harrison, G.G., Bul. A. A.B., \& Kinch, J.E. Changes underlying halothane-induced malignant hyperpyrexia in Landrace pigs. Nature 226: 653 (1970),

10. Cummings, J.N., Brit, B.A. \& Kalow, W. A clinical report on two spontaneous cases of malignant hyperthermia in swine Canad. Vet. J. (in press, 1972).

11. FLowers, C.E. Jn. Factors related to the placental transfer of thiopental in the hemochorial placenta. Amer, J. Obstet. \& Gymec. 85: 646 (1963).

12. McKechnie, F.B. \& Converse, J.G. Placental transmission of thiopental. Amer. J. Obstet. \& Gynec. 70: 639 (1955). 